\title{
Article \\ Simulation of Extended Wavelength Avalanche Photodiode with the Type-II Superlattice Absorption Layer
}

\author{
Wei-Lin Zhao (D), Wei Wang, Chen Liu, Ze-Peng Hou, Hai-Feng Ye, Run-Yu Huang, Zai-Bo Li, Jia-Xin Zhang, \\ Xue-Yan Yang, Hong-Xia Zhu and Yan-Li Shi *
}

Citation: Zhao, W.-L.; Wang, W.; Liu C.; Hou, Z.-P.; Ye, H.-F.; Huang, R.-Y.; Li, Z.-B.; Zhang, J.-X.; Yang, X.-Y.; Zhu, H.-X.; et al. Simulation of Extended Wavelength Avalanche Photodiode with the Type-II Superlattice Absorption Layer. Crystals 2021, 11, 1210. https:// doi.org/10.3390/cryst11101210

Academic Editors: Wen Lei, Baolai Liang, Junqi Liu and Weiming Cheng

Received: 9 September 2021

Accepted: 4 October 2021

Published: 7 October 2021

Publisher's Note: MDPI stays neutral with regard to jurisdictional claims in published maps and institutional affiliations.

Copyright: (c) 2021 by the authors. Licensee MDPI, Basel, Switzerland. This article is an open access article distributed under the terms and conditions of the Creative Commons Attribution (CC BY) license (https:// creativecommons.org/licenses/by/ $4.0 /)$.
School of Physics and Astronomy, Yunnan University, Kunming 650091, China; zhaoweilin@mail.bnu.edu.cn (W.-L.Z.); wangwei@mail.ynu.edu.cn (W.W.); 13808713479@163.com (C.L.); shichen@mail.ynu.edu.cn (Z.-P.H.); A13398710712@163.com (H.-F.Y.); Huangry1998@163.com (R.-Y.H.); zaiboli_yun@163.com (Z.-B.L.); zjxinqushida@163.com (J.-X.Z.); yangxueyan1103@163.com (X.-Y.Y.); zhuhongxi19960623@163.com (H.-X.Z.)

* Correspondence: shiyanli@ynu.edu.cn

\begin{abstract}
The relationship between the performance of avalanche photodiode (APD) and structural parameters of the absorption, grading, and multiplication layers has been thoroughly simulated and discussed using the equivalent materials approach and Crosslight software. Based on separate absorption, grading, charge, and multiplication (SAGCM) structure, the absorption layer of APD was replaced with InGaAs/GaAsSb superlattice compared to conventional InGaAs/InP SAGCM APD. The results indicated that the breakdown voltage increased with the doping concentration of the absorption layer. When the thickness of the multiplication layer increased from $0.1 \mu \mathrm{m}$ to $0.6 \mu \mathrm{m}$, the linear range of punchthrough voltage increased from $16 \mathrm{~V}$ to $48 \mathrm{~V}$, and the breakdown voltage decreased at first and then increased when the multiplication layer reached the critical thickness at $0.35 \mu \mathrm{m}$. The grading layer could not only slow down the hole carrier, but also adjust the electric field. The dark current was reduced to about $10 \mathrm{nA}$ and the gain was over 100 when the APD was cooled to $240 \mathrm{~K}$. The response wavelength APD could be extended to $2.8 \mu \mathrm{m}$ by fine tuning the superlattice parameters. The simulation results indicated that the APD using superlattice materials has potential to achieve a long wavelength response, a high gain, and a low dark current.
\end{abstract}

Keywords: APD; extended wavelength; InGaAs/GaAsSb superlattice; I-V characteristics; electric field distribution

\section{Introduction}

In recent years, with the growing concern about eye safety in light detection and ranging (LiDAR) [1] and capacity saturation in traditional communication wavebands, the extended wavelength avalanche photodiode has attracted increasing attention. By extending the operating wavelength from conventional $1.55 \mu \mathrm{m}$ to more than $2 \mu \mathrm{m}$, the extended wavelength avalanche photodiode has important applications in LiDAR. Avalanche photodiodes (APDs) are ideal for the operation in this spectrum range because its internal gain provides a higher sensitivity than conventional photodiodes, which significantly improves the sensitivity of the receiver. At present, the main materials that can respond to $2 \mu \mathrm{m}$ or longer wavelength include InGaAs [2-4] with high indium components, $\mathrm{HgCdTe}$, and InAsAlSb. When the InGaAs devices are used with response wavelength exceeding $2 \mu \mathrm{m}$, the indium content must be increased to nearly $80 \%$, leading to a lattice mismatch with the InP material and increasing material defects. The dark current density is several orders higher than standard $\operatorname{In}_{0.53} \mathrm{Ga}_{0.47}$ As devices. In addition, extended wavelength InGaAs devices have a lower quantum efficiency (QE) of 50-60\% [5]. The $\mathrm{HgCdTe}$ material can provide an adjustable band gap in the range of $0-1.6 \mathrm{eV}$, making it an excellent absorption material for all infrared bands. It has a high $\mathrm{QE}(>70 \%$, at room temperature) in the range of 1-3- $\mu \mathrm{m}$ short-wave infrared (SWIR), but the CdZnTe substrates required for the growth 
of $\mathrm{HgCdTe}$ material are expensive [6]. Compared with InP-based III-V devices, the $\mathrm{HgCdTe}$ device preparation process has difficulties and a low yield rate. Consequently, $\mathrm{HgCdTe}$ is facing challenges in many commercial applications because of its high ratio of cost to performance. InSb is a primary material candidate for 2- $\mu \mathrm{m}$ APD applications. Although this material exhibits very low excess noise, it must be operated at cryogenic temperatures to reduce dark current. Such operating temperatures prohibit compact receiver production, as the required cryogenic system is both complex and many times larger than the detector itself [7]. APDs based on group III-V. such as AlInAsSb and InGaAs/GaAsSb superlattice materials, have become a hot spot for domestic and international research due to their excellent performance and suitable detection wavelength range. In contrast, the type II superlattice (T2SL) material $[8,9]$ is a material system under development in recent years. With outstanding growth uniformity [10] and excellent band structure engineering capability [11,12], T2SLs are versatile candidates for enhanced IR detection and imaging [9] from near-infrared $[13,14]$ to long wavelength infrared (LWIR) and very long wavelength infrared (VLWIR) [15-18].

In this paper, we use Crosslight software to simulate the layer structure of T2SL extended wavelength APD and research the relationship between each layer of the APD. In the Crosslight simulation, the energy band structure is based on the Schrodinger equation, and the transport characteristics are based on the drift-diffusion model, the impact ionization model, and the Poisson equation. The device characteristics were simulated by Crosslight. In addition, the layer structure design of $\operatorname{In}_{0.53} \mathrm{Ga}_{0.47} \mathrm{As} / \mathrm{GaAs}_{0.51} \mathrm{Sb}_{0.49} \mathrm{~T} 2 \mathrm{SL}$ extended wavelength APD was also discussed.

\section{Layer Structure Design}

In this paper, we used the equivalent material method for dealing with the energy structure and physical parameters of superlattice materials. First of all, several periods of superlattice materials were used to build a layer structure model, the energy band structure was simulated, and the results were approximated as that of the equivalent bulk material. Then, the parameters of the equivalent bulk material corresponding to the whole absorption layer of the superlattice was brought to the SAGCM APD structure to stimulate. This method has been used previously to calculate InAs/GaSb T2SL nBn detectors by Shi Yanli project group of Yunnan University in 2019 [19,20]. A group in the Beijing University of Posts and telecommunications has also used this method to calculate the energy band of superlattice materials in 2019 [21]. In this way, the equivalent bulk material was stimulated instead of hundreds of layers of superlattice materials, which will save a lot of time as it is easy to verify the results of the whole simulation materials.

Figure 1 shows the device layer structure diagram simulated in this paper. From top to bottom, there is the $\mathrm{p}+\mathrm{InP}$ layer, the $\mathrm{i}-\mathrm{InP}$ multiplication layer, the $\mathrm{n}+\mathrm{InP}$ charge layer, the InGaAsP grading layer, the InGaAs/GaAsSb superlattice absorption layer, the InGaAs buffer layer, the n-type heavily doped InP substrate, and the ohmic contact metal electrode. Generally, the InGaAsP grading layer has 2-5 layers, which can slow down the hole barrier formed by the valence band shift between the InGaAs/GaAsSb absorption layer and the InP multiplication layer, thus reducing the accumulation of hole carriers at the heterojunction barrier. The $\mathrm{n}-\mathrm{InP}$ charge layer is used to adjust the electric field distribution between the multiplication layer and the absorption layer, so that the absorption layer electric field can make sure the carriers overcome the heterojunction barrier between the absorption layer and the charge layer and drifting to the multiplication region, meanwhile reducing the absorption region electric field as much as possible to decrease the dark current. In this paper, the wide band gap material InP is used as the multiplication layer, which means the hole multiplication.

As shown in Figure 2, the energy band structure of a 5-nm- $\operatorname{In}_{0.53} \mathrm{Ga}_{0.47} \mathrm{As} / 5 \mathrm{~nm}-$ $\mathrm{GaAs}_{0.51} \mathrm{Sb}_{0.49}$ superlattice material was calculated with an 8-band K.P model. The red solid lines from top to bottom are L-band, $\Gamma$-band, heavy hole band, and light hole band. The two blue solid lines from top to bottom are the upper and lower edges of the bandgap of 
the equivalent material. The affinity of the equivalent material is equal to the affinity of the $\mathrm{GaSb}$ material plus the absolute value which is equal to (the bottom of the conduction band of the equivalent material subtracts the bottom of the conduction band of the GaSb material). It can be seen from Figure 2 that the band gap of $5-\mathrm{nm}-\mathrm{In}_{0.53} \mathrm{Ga}_{0.47} \mathrm{As} / 5 \mathrm{~nm}-\mathrm{GaAs}_{0.51} \mathrm{Sb}_{0.49}$ superlattice material is $0.43 \mathrm{eV}$. Figure 3 shows the energy band structure of the SAGCM APD device at equilibrium and breakdown an with equivalent material method.

\begin{tabular}{|c|}
\hline $\mathrm{P}+$ doped InP cap layer \\
\hline Undoped InP multiplication layer \\
\hline $\mathrm{n}+\operatorname{InP}$ charge layer \\
\hline InGaAsP grading layer \\
\hline \hline InGaAs-GaAsSD ape-II Supetatices \\
\hline \hline InGaAs buffer layer \\
\hline InP substrate \\
\hline $\mathrm{E}$-contact metallization \\
\hline
\end{tabular}

Figure 1. Diagram of the device layer structure.

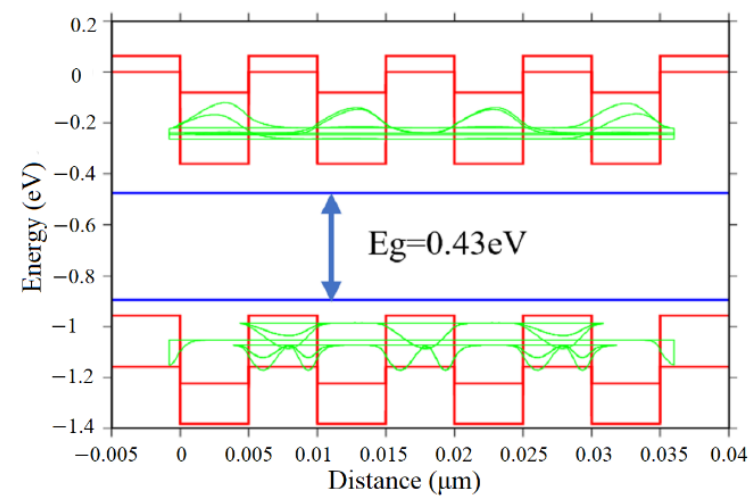

Figure 2. Energy band structure of the $5-\mathrm{nm}-\mathrm{In}_{0.53} \mathrm{Ga}_{0.47} \mathrm{As} / 5 \mathrm{~nm}-\mathrm{GaAs}_{0.51} \mathrm{Sb}_{0.49}$ superlattice material.

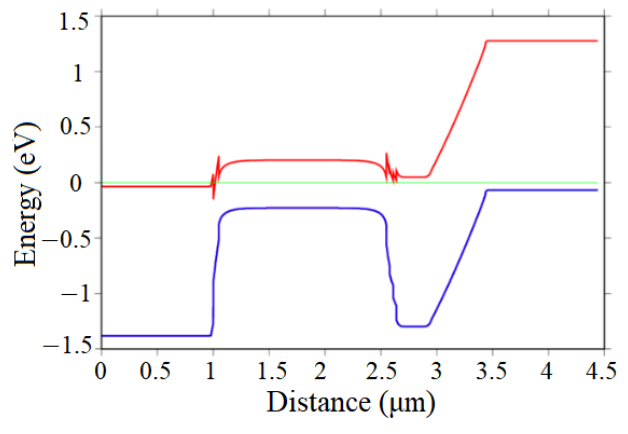

(a)

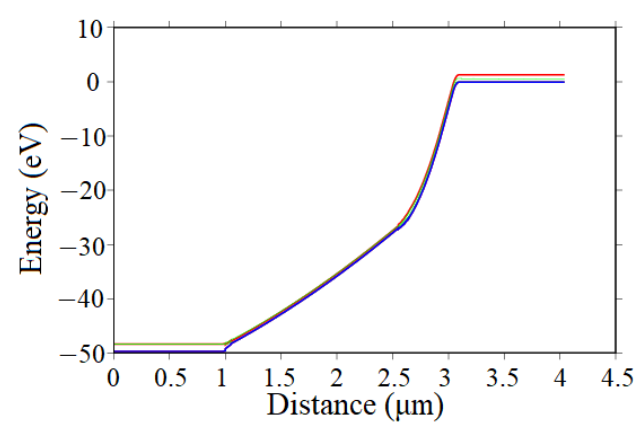

(b)

Figure 3. Calculated energy band structure of the SAGCM APD device with equivalent material method. (a) at equilibrium; (b) at breakdown voltage. 


\section{Discussion}

The device structure simulation is performed by using equivalent material method. The effect of each layer structural parameters to the electric field and the I-V characteristics of the device are discussed in Table 1.

Table 1. The important parameters used in the simulation.

\begin{tabular}{ccc}
\hline Parameters & Value & Units \\
\hline Absorption layer thickness & $1.5,2,2.5,3$ & $\mu \mathrm{m}$ \\
Multiplication layer thickness & $0.1,0.2,0.3,0.4,0.5,0.6$ & $\mu \mathrm{m}$ \\
Doping concentration of grading layer & $7 \times 10^{22}, 8 \times 10^{22}, 9 \times 10^{22}, 1 \times 10^{23}$ & $\mathrm{~m}^{-3}$ \\
Temperature & $240,270,300$ & $\mathrm{~K}$ \\
\hline
\end{tabular}

Firstly, for the absorption layer, the forbidden band width of the material has a relationship with the long wavelength limit as follows [22].

$$
\lambda(\mu \mathrm{m})=1.24 / \mathrm{E}_{\mathrm{g}}(\mathrm{eV})
$$

$\mathrm{E}_{\mathrm{g}}$ is the band gap of the material, and the band gap of $\operatorname{In}_{0.53} \mathrm{Ga}_{0.47} \mathrm{As} / \mathrm{GaAs}_{0.51} \mathrm{Sb}_{0.49}$ superlattice material at $300 \mathrm{k}$ is $0.43 \mathrm{eV}$, and the cut-off wavelength can be calculated from the above Equation (1) to be about $2.8 \mu \mathrm{m}$. For photons with energy greater than the band gap, the absorbed efficiency of the absorption layer can be expressed by absorption coefficient and reflection coefficient as follows [22].

$$
\mathrm{P}_{\mathrm{abs}}(\mathrm{x})=(1-\mathrm{R})(1-\exp (-\mathrm{ax}))
$$

In the above equation, $\mathrm{P}_{\mathrm{abs}}(\mathrm{x})$ represents the efficiency that the photon will be absorbed at the absorption position $\mathrm{x} . \mathrm{R}$ is the reflection coefficient of the material (Here $\mathrm{R}$ is approximately 0$)$. $\mathrm{a}$ is the absorption coefficient of the material. The higher the $\mathrm{P}_{\mathrm{abs}}(\mathrm{x})$, the higher the efficiency that a photon will be detected in the material. $\operatorname{In}_{0.53} \mathrm{Ga}_{0.47} \mathrm{As} / \mathrm{GaAs}_{0.51} \mathrm{Sb}_{0.49}$ superlattice material has an absorption coefficient of $6000 \mathrm{~cm}^{-1}$ at $1.55 \mu \mathrm{m}$ and $2000 \mathrm{~cm}^{-1}$ at $2 \mu \mathrm{m}$ [5]. These values are substituted into the above equation (2) to obtain the absorption efficiency distribution of photons in the $\operatorname{In}_{0.53} \mathrm{Ga}_{0.47} \mathrm{As} / \mathrm{GaAs}_{0.51} \mathrm{Sb}_{0.49}$ superlattice material (shown in Figure 4).

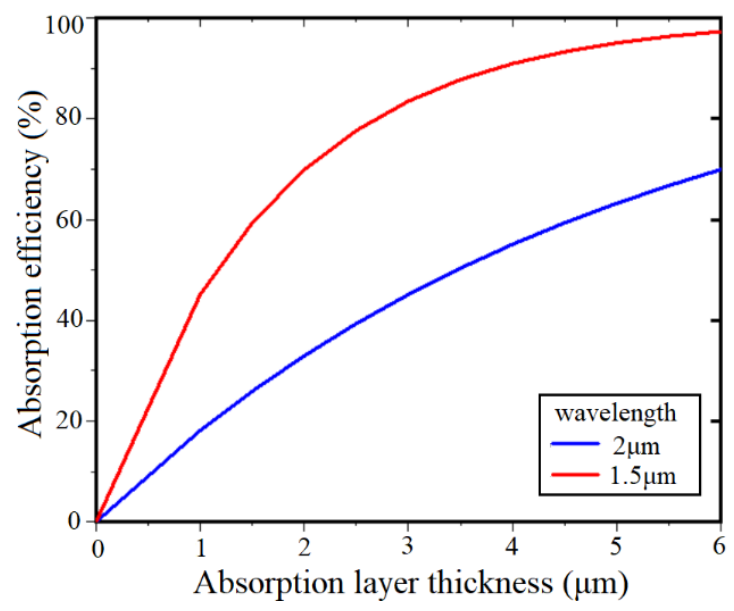

Figure 4. Diagram of absorption efficiency as a function of thickness.

It can be seen from Figure 4 that, for the photon at $2 \mu \mathrm{m}$ with a wavelength indicated as the blue curve, the absorption efficiency is $30 \%$ when the thickness of the absorption layer is $1.5 \mu \mathrm{m}$, and the absorption efficiency increases by $15 \%$ when the absorption thickness changes from $1.5 \mu \mathrm{m}$ to $3 \mu \mathrm{m}$. Meanwhile, the material also has excellent absorption 
efficiency for a photon with a 1.5- $\mu \mathrm{m}$ wavelength, and the absorption efficiency can reach more than $80 \%$ when the thickness of the absorption layer is $3 \mu \mathrm{m}$. From the above results, it can be seen that the photon absorption efficiency is increased by enlarging the absorption thickness, then tends to a limit value as the layer thickness increases, and the absorption layer cannot be made too thick in the actual avalanche photodiode. Figure 5 shows the simulated I-V characteristic curves of the device at $300 \mathrm{~K}$. It can be seen that the photocurrent increases owing to the absorption layer thickness increases. The dark current increases from $2.2 \times 10^{-6} \mathrm{~A}$ (the absorption layer thickness is $1.5 \mu \mathrm{m}$ ) to $3.6 \times 10^{-6} \mathrm{~A}$ (the absorption layer is $3 \mu \mathrm{m}$ ). This is because the defects also increase when the thickness of the absorption layer increases. In addition, in practical situations, the response time can be raised by increasing of the absorption layer thickness. In single-photon detection mode, the increase in the absorption layer thickness will lead to the time jitter and dark count increasing.

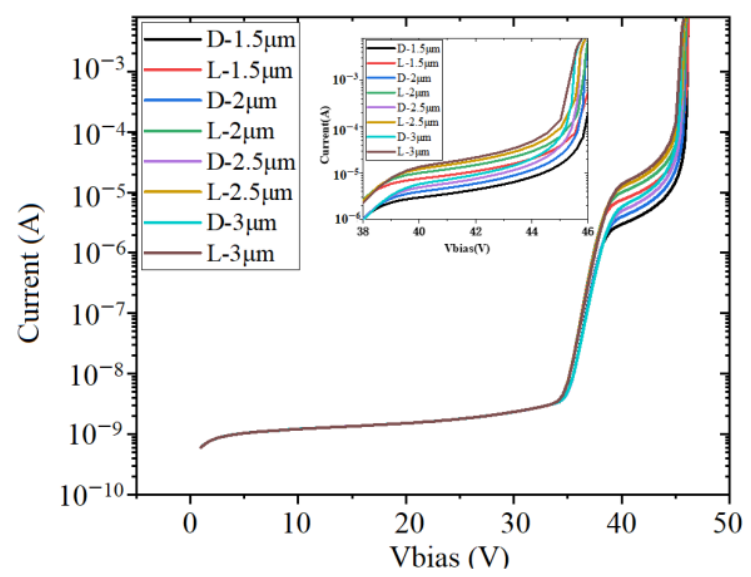

Figure 5. Simulation results of I-V characteristics of devices with different absorption layer thicknesses (Note. D: dark current; L: light current; the inserted figure is a partial enlargement of Figure 5).

The effect of multiplication layer thickness on the I-V characteristics are simulated, and the results are shown in Figure 6. The multiplication layer concentration is $1 \times 10^{21} \mathrm{~m}^{-3}$ at $300 \mathrm{~K}$. When the multiplication layer thickness is $0.1 \mu \mathrm{m}$, the dark current is $1.3 \times 10^{-6} \mathrm{~A}$ at the punchthrough voltage point; with the increase in bias voltage, the current of the detector appears obvious in this step-by-step phenomenon. Increasing the multiplication layer thickness, the dark current also increases, resulting from the generation-recombination current.

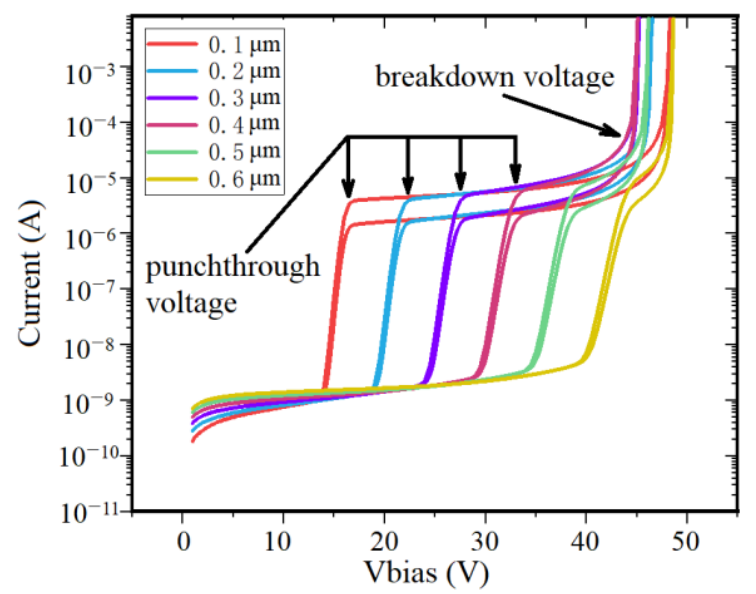

Figure 6. I-V curve of the device with different multiplication thickness.

As shown in Figure 7, the relationship between the multiplication layer and the device punchthrough and break down voltages is obtained by adjusting the thickness of the multi- 
plication layer. Here, the dark current of $1 \times 10^{-5} \mathrm{~A}$ is set as the breakdown voltage point $\left(\mathrm{V}_{\mathrm{br}}\right)$. The breakdown voltage decreases from $46 \mathrm{~V}$ to $42 \mathrm{~V}$ as the multiplication layer thickness increases from $0.1 \mu \mathrm{m}$ to $0.35 \mu \mathrm{m}$. Then, the breakdown voltage increases from $42 \mathrm{~V}$ to $47 \mathrm{~V}$ as the multiplication layer increases from $0.35 \mu \mathrm{m}$ to $0.6 \mu \mathrm{m}$. This non-monotonic situation can be explained as follows. When the multiplication layer is less than $0.35 \mu \mathrm{m}$, the higher electrical field and external bias is required to obtain the sufficient multiplication for breakdown, so the multiplication layer is thinner and the breakdown voltage is higher. When the multiplication layer is relatively thick, the increase in breakdown voltage is a result of the reduction in the electric field of the multiplication layer, so external bias is also needed to increase the avalanche breakdown. The punchthrough voltage increases significantly due to the increased multiplication layer thickness; this is because higher external bias voltage is required to completely deplete the multiplication region. The electric field distribution for different multiplication layer thicknesses is depicted in Figure 8, and the interpretation can be well verified by looking at the electric field distribution near the breakdown.

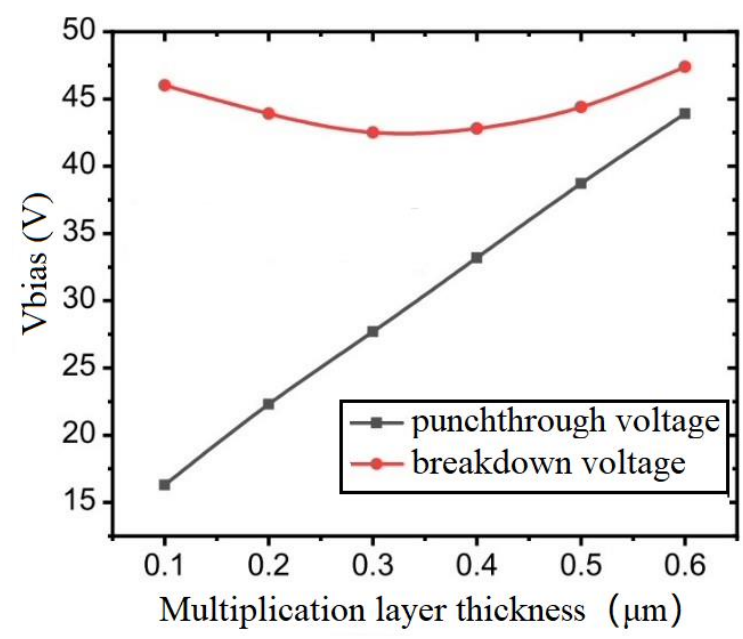

Figure 7. The change in punchthrough voltage and breakdown voltage with the multiplication layer thickness (the breakdown voltage is set at the position where the dark current is $10^{-5} \mathrm{~A}$ ).

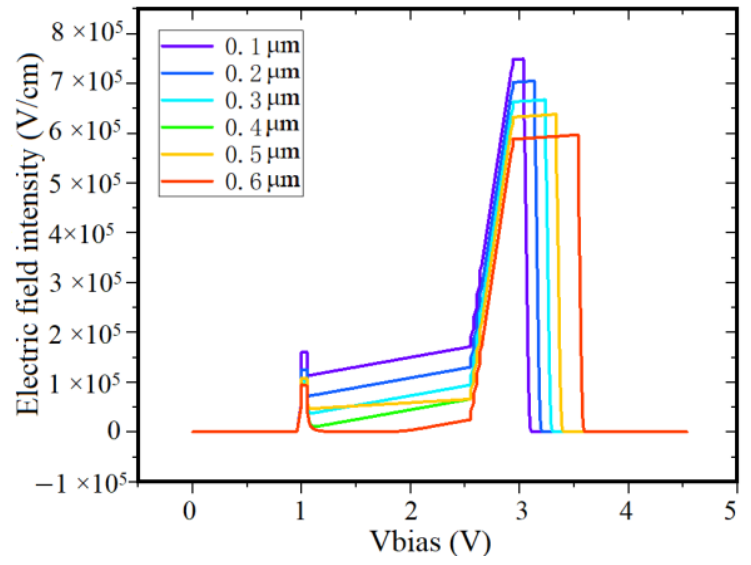

Figure 8. The electric field distribution of the device varies with the multiplication layer thickness under breakdown bias.

In the SAGCM stucture, the charge layer is InP whose forbidden band width is $1.35 \mathrm{eV}$, while the forbidden band width of the absorption layer $\mathrm{In}_{0.53} \mathrm{Ga}_{0.47} \mathrm{As} / \mathrm{GaAs}_{0.51} \mathrm{Sb}_{0.49} \mathrm{~T} 2 \mathrm{SL}$ is about $0.43 \mathrm{eV}$. The band gap between the two layers is too large, and it is easy to form interfacial barriers to accumulate carriers. Therefore, a grading layer is added between the charge layer and the absorption layer to make the energy bands match between the 
two materials, where the band gap can be made to vary from 0.75 to $1.35 \mathrm{eV}$ by adjusting the components of $\mathrm{In}_{1-\mathrm{x}} \mathrm{Ga}_{\mathrm{x}} \mathrm{AsP}$ materials. It is found from the simulation results that the grading layer can regulate the electric field, such as the InP charge layer. Figures 9 and 10 show the electric field and the I-V characteristic curves with different grading layer doping concentration, respectively. The electric field of the absorption layer becomes higher when the doping concentration of the grading layer is reduced from $1 \times 10^{23} \mathrm{~m}^{-3}$ to $7 \times 10^{22} \mathrm{~m}^{-3}$, and the punchthrough voltage decreases from $40 \mathrm{~V}$ to $36 \mathrm{~V}$ (change of $4 \mathrm{~V}$ ) which comes from easily depletion of the lower doping concentration. On the contrary, the breakdown voltage of the device increases from $43.5 \mathrm{~V}$ to $47 \mathrm{~V}$ (increase of $3.5 \mathrm{~V}$ ), which implies that the electrical filed in the multiplication layer decreases as the doping concentration of the grading layer decreases.

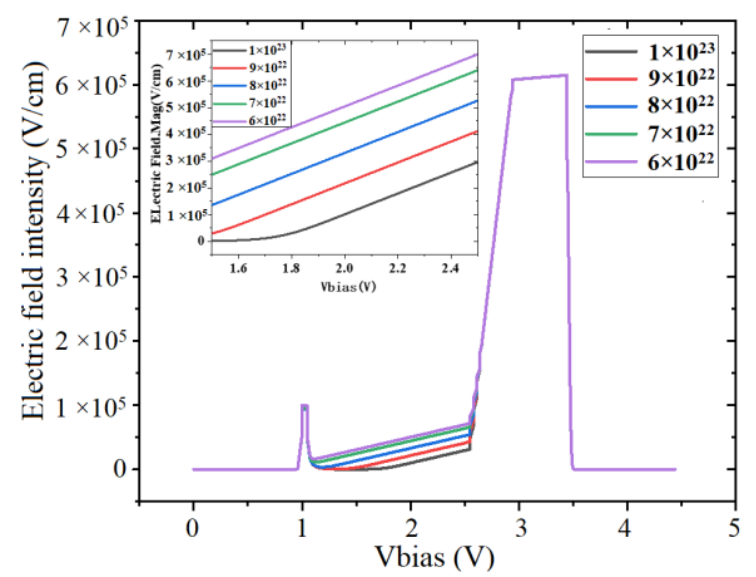

Figure 9. Electric field distribution diagram under different doping concentration of grading layer, doping concentration unit: $\mathrm{m}^{-3}$. (Note. The inserted figure is a partial enlargement of Figure 9).

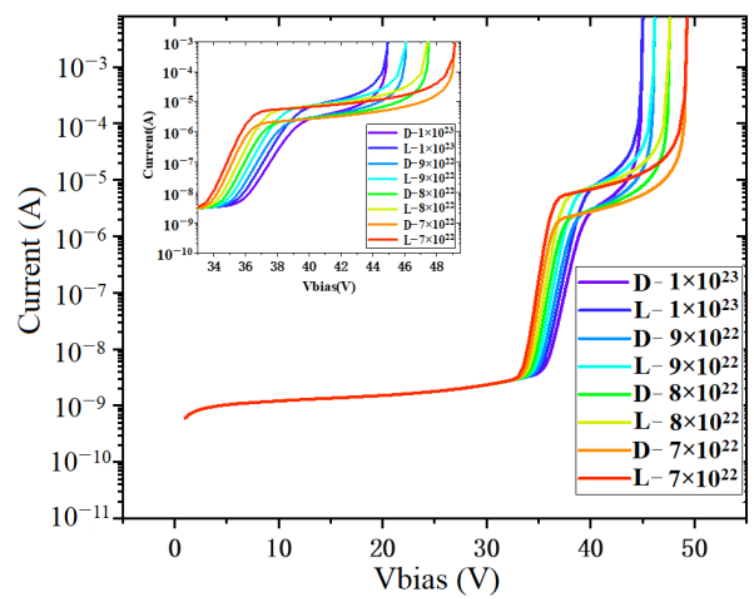

Figure 10. Characteristic curves of $\mathrm{I}-\mathrm{V}$ at different doping concentrations, doping concentration unit: $\mathrm{m}^{-3}$. (Note. D: dark current; L: light current; the inserted figure is a partial enlargement of Figure 10).

\section{Temperature Dependence}

When the absorption layer is replaced by the InGaAs/GaAsSb superlattice other than InGaAs layer, the band gap of the absorption layer becomes narrower and the dark current increases. In order to decrease the dark current, the operation temperature is required to reduce. Therefore, the situation after cooling is simulated, and the results are shown in Figure 11. From the figure, it can be seen that the dark current decreases by an order of magnitude when the temperature decreases by $30^{\circ} \mathrm{C}$. When the temperature is $240 \mathrm{k}$, the dark current at the punchthrough voltage point is $10 \mathrm{nA}$. It can be seen that the change in temperature affects the value of breakdown voltage, and the breakdown voltage becomes about $4 \mathrm{~V}$ smaller as for every $30^{\circ} \mathrm{C}$ decrease in temperature. 


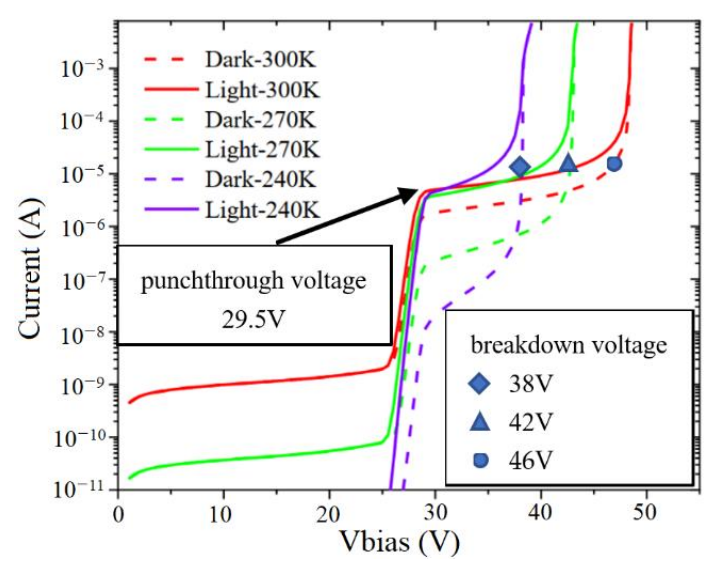

Figure 11. I-V characteristic curves at different temperatures.

For APDs, the impact ionization is affected by temperature. The average free path of carriers increases as temperature decreases, which increases the impact ionization coefficient. It shows that the device is more prone to avalanche under a small bias voltage, that is, the breakdown voltage decreases with the temperature. The dependence of breakdown voltage on temperature is $0.13 \mathrm{~V} /{ }^{\circ} \mathrm{C}$. This is about the same order of magnitude as the temperature drift coefficient of traditional InGaAs/InP APD [23].

Under the illumination of the $2-\mu \mathrm{m}$ wavelength, the incident light power is $4 \mu \mathrm{w}$ and the device diameter is $50 \mu \mathrm{m}$. The gain can be calculated by photocurrent and dark current [24].

$$
M=\frac{I_{p}-I_{d}}{I_{p 0}-I_{d 0}}
$$

In formula (3), $I_{P 0}$ and $I_{d 0}$ are marked as the photocurrent and dark current at the unit gain point $(M=1)$, where the unit gain point is at the punchthrough voltage point $(29.5 \mathrm{~V}$ under $240 \mathrm{~K}) . \mathrm{I}_{\mathrm{p}}$ and $\mathrm{I}_{\mathrm{d}}$ are the photocurrent and dark current at the different bias. When the temperature drops to $240 \mathrm{~K}$, the gain changes with the bias voltage (as shown in Figure 12), and the gain of the device at the breakdown point exceeds 300 . In contrast, for comparison, Jones et al. have reported an AlInAsSb APD [25] with a gain of 60 at the condition of room temperature, 2- $\mu \mathrm{m}$ illumination, and a breakdown point of about $43-\mathrm{V}$ bias. Dumas et al. have reported a HgCdTe APD [26] with a gain of 21 at the condition of $185 \mathrm{~K}, 2-\mu \mathrm{m}$ illumination, and $12-\mathrm{V}$ bias.

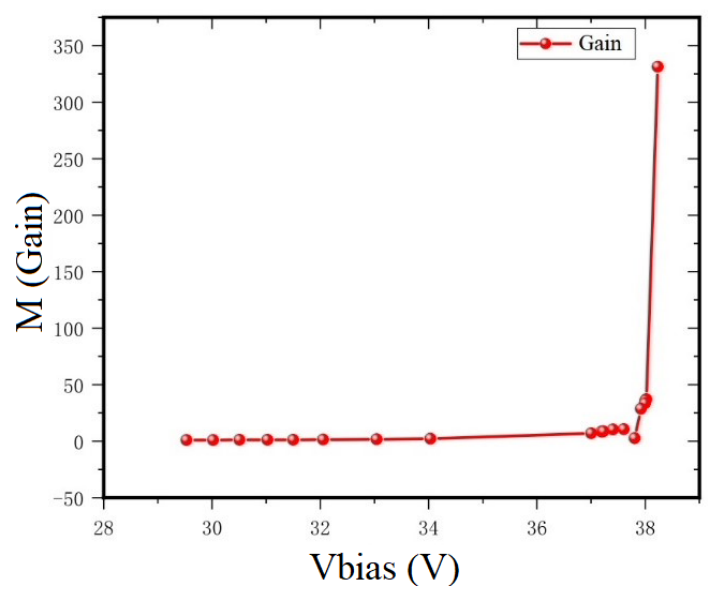

Figure 12. The gain curve of the device at $240 \mathrm{~K}$ as a function of bias voltage. 


\section{Conclusions}

In summary, an APD based on short-wave infrared InGaAs/GaAsSb T2SL was simulated using Crosslight software. The I-V characteristics and the electric field distribution of the absorption, grading, and multiplication layers were analyzed. Furthermore, the effect of temperature on the I-V characteristics and the gain of the device was discussed. The device had a cutoff wavelength of $2.8 \mu \mathrm{m}$. The dependence of the breakdown voltage on temperature was found to be $0.13 \mathrm{~V} /{ }^{\circ} \mathrm{C}$. The dark current of the device decreased by about one order of magnitude for every $30^{\circ} \mathrm{C}$ decrease in temperature. The gain of the device at the breakdown point exceeded 300 at $240 \mathrm{~K}$. The stimulation results indicate that the $5 \mathrm{~nm}-\mathrm{In}_{0.53} \mathrm{Ga}_{0.47} \mathrm{As} / 5 \mathrm{~nm}-\mathrm{GaAs}_{0.51} \mathrm{Sb}_{0.49}$ superlattice material can be used as an absorption layer to achieve low dark current and high gain characteristics in the cutoff wavelength of $2.8 \mu \mathrm{m}$.

Author Contributions: Data curation, W.-L.Z. and W.W.; Simulation calculation, X.-Y.Y. and C.L.; Basis parameter discussion and determination analysis, J.-X.Z. and H.-X.Z.; Writing-review \& editing, Z.-P.H., H.-F.Y. and R.-Y.H.; W.-L.Z. and Z.-B.L. Theoretical calculation guidance and paper review, Y.-L.S. All authors have read and agreed to the published version of the manuscript.

Funding: This work was supported by the major science and technology project of Yunnan province 2018ZI002, and the Yunnan University's Research Innovation Fund for Graduate Students (No. 2020290).

Acknowledgments: This work was supported by the major science and technology project of Yunnan province 2018ZI002, and the Yunnan University's Research Innovation Fund for Graduate Students (No. 2020290). Thanks to the cooperation of the project team members and the guidance of professor Yan-Li Shi.

Conflicts of Interest: The authors declare no conflict of interest.

\section{References}

1. Scholle, K.; Lamrini, S.; Koopmann, P.; Fuhrberg, P. $2 \mu \mathrm{m}$ laser sources and their possible applications. In Frontiers in Guided Wave Optics and Optoelectronics; Pal, B., Ed.; IntechOpen: London, UK, 2010.

2. Dries, J.C.; Gokhale, M.R.; Thomson, K.J.; Hull, S.R. Strain compensated $\operatorname{In}_{1-x} \mathrm{Ga}_{x} \mathrm{As}(\mathrm{x}<0.47)$ quantum well photodiodes for extended wavelength operation. Appl. Phys. Lett. 1998, 73, 2263-2265.

3. Wada, M.; Hosomatsu, H. Wide wavelength and low dark current lattice-mismatched InGaAs/InAsP photodiodes grown by metalorganic vapor-phase epitaxy. Appl. Phys. Lett. 1994, 64, 1265-1267. [CrossRef]

4. Miao, G.; Zhang, T.; Zhang, Z.; Jin, Y. Extended spectral response in In0.82Ga0.18As/InP photodetector using InP as a window layer grown by MOCVD. CrystEngComm 2013, 15, 8461-8464. [CrossRef]

5. Easley, J.; Martin, C.R.; Ettenberg, M.H.; Phillips, J. InGaAs/GaAsSb type-II superlattices for short-wavelength infrared detection. J. Electron. Mater. 2019, 48, 6025-6029. [CrossRef]

6. Olver, I. Defect Characterization of Molecular Beam Modular Epitaxially Grown HgCdTe Samples; Army Research Lab: Adelphi, MD, USA, 2009.

7. Jones, A.H.; March, S.D.; Bank, S.R.; Campbell, J.C. Low-noise high-temperature AllnAsSb/GaSb avalanche photodiodes for 2- $\mu$ m applications. Nat. Photonics 2020, 14, 559-563. [CrossRef]

8. Sai-Halasz, G.A.; Tsu, R.; Esaki, L. A new semiconductor superlattice. Appl. Phys. Lett. 1977, 30, 651-653. [CrossRef]

9. Razeghi, M. Focal Plane Arrays in Type II-Superlattices. U.S. Patent 6864552B2, 3 August 2005.

10. Nguyen, B.M.; Chen, G.; Hoang, M.A.; Razeghi, M. Growth and characterization of long-wavelength infrared type-II superlattice photodiodes on a 3-in GaSb wafer. IEEE J. Quantum Electron. 2011, 47, 686-690. [CrossRef]

11. Hoang, A.M.; Dehzangi, A.; Adhikary, S.; Razeghi, M. High performance bias-selectable three-color Short-wave/Mid-wave/Longwave Infrared Photodetectors based on Type-II InAs/GaSb/AlSb superlattices. Sci. Rep. 2016, 6, 24144. [CrossRef] [PubMed]

12. Haddadi, A.; Chen, G.; Chevallier, R.; Hoang, A.M.; Razeghi, M. InAs/ InAs $1-{ }_{x} \mathrm{Sb}_{\mathrm{x}}$ type-II superlattices for high performance long wavelength infrared detection. Appl. Phys. Lett. 2014, 105, 121104. [CrossRef]

13. Goh, Y.L.; Ong, D.S.G.; Zhang, S.; Ng, G.S.; Tan, C.H.; David, J.P.R. Type-II photodiode and APD for detection in the 2-2.5 $\mu$ m wavelength range. In Proceedings of the 22nd Annually Meeting of the IEEE Lasers and Electro-Optics Society Meeting Conference, Belek-Antalya, Turkey, 4-8 October 2009.

14. Ong, D.S.G.; Ng, J.S.; Goh, Y.L.; Tan, C.H.; Zhang, S.Z.; David, J.P.R. InAlAs Avalanche Photodiode With Type-II Superlattice Absorption for Detection Beyond $2 \mu \mathrm{m}$. Electron Devices. IEEE Trans. Electron Devices 2011, 58, 486-489. [CrossRef]

15. Haddadi, A.; Suo, X.V.; Adhikary, S.; Dianat, P.; Chevallier, R.; Hoang, A.M.; Razeghi, M. High-performance short-wavelength infrared photodetectors based on type-II InAs/InAs ${ }_{1-x} \mathrm{Sb}_{x} / \mathrm{AlAs}_{1-\mathrm{x}} \mathrm{Sb}_{\mathrm{x}}$ superlattices. Appl. Phys. Lett. $2015,107,141104$. [CrossRef] 
16. Wei, Y.; Bae, J.; Gin, A.; Hood, A.; Razeghi, M. High quality type II InAs/GaSb superlattices with cutoff wavelength 3.7 $\mu$ m using interface engineering. J. Appl. Phys. 2003, 94, 4720-4722. [CrossRef]

17. Wei, Y.; Gin, A.; Razeghi, M. Type II InAs/GaSb superlattice photovoltaic detectors with cutoff wavelength approaching $32 \mu \mathrm{m}$. Appl. Phys. Lett. 2002, 81, 3675-3677. [CrossRef]

18. Hoang, A.M.; Chen, G.; Haddadi, A.; Abdollahi Pour, S.; Razeghi, M. Demonstration of shortwavelength infrared photodiodes based on type-II InAs/GaSb/AlSb superlattices. Appl. Phys. Lett. 2012, 100, 211101. [CrossRef]

19. Liu, C.; Zhu, H.; Yang, X.; Zeng, H.; Wang, J.; Shi, Y. Dark current simulation of InAs/GaSb ii type super-lattice nBn detectors with equivalent material method. In AOPC 2019: Optical Sensing and Imaging Technology; SPIE: Beijing, China, 2019.

20. Wang, J.; Zhu, H.X.; Zeng, H.; Yang, X.Y.; Liu, C.; Shi, Y.-L. The study of the electric field in nBn InAsSb/AlAsSb medium wavelength infared detectors. In AOPC 2019: Optical Sensing and Imaging Technology; SPIE: Beijing, China, 2019.

21. Wang, K. Band Anti-Cross Effects of Gallium/Indium Semiconductor Alloy. Master's Thesis, Beijing University of Posts and Telecommunications, Beijing, China, June 2019.

22. Ma, J. Design of Single Photon Avalanche Diodes. Ph.D. Thesis, University of Science and Technology of China, Hefei, China, June 2014.

23. Ma, C.F.; Deen, M.J.; Tarof, L.E.; Yu, J.C. Temperature dependence of breakdown voltages in separate absorption, grading, charge, and multiplication InP/InGaAs avalanche photodiodes. IEEE Trans. Electron Devices 1995, 42, 810-818. [CrossRef]

24. He, J. Analyses on Dark Current Components of Infrared Avalanche Photodiode and Mechanism Research. Master's Thesis, University of Chinese Academy of Sciences, Beijing, China, April 2017.

25. Jones, A.H.; March, S.D.; Bank, S.R.; Campbell, J. CAl $\mathrm{In}_{1-\mathrm{x}} \mathrm{As}_{\mathrm{y}} \mathrm{Sb}_{1-\mathrm{y}}$ separate absorption, charge, and multiplication avalanche photodiodes for 2- $\mu \mathrm{m}$ detection. In IEEE Photonics Conference (IPC); IEEE: San Antonio, TX, USA, 2019.

26. Dumas, A.; Rothman, J.; Gibert, F.; Lasfargues, G.; Zanatta, J.P.; Edouart, D. Performances of a HGCDTE APD based detector with electric cooling for 2- $\mu \mathrm{m}$ DIAL/IPDA applications. In Proceedings of the 27th International Laser Radar Conference, New York, NY, USA, 7 June 2016. 